\title{
Characteristics of Secondary Mountain Disaster Chain in Wenchuan Earthquake
}

\author{
Ranran Pei, Zhenqiang Ni, Zhaobo Meng*, Baoliang Zhang*, Rumeng Liao \\ School of Architecture and Civil Engineering, Liaocheng University, Liaocheng, China \\ Email address: \\ 1750190496@qq.com (Ranran Pei),nizhenqiang@1cu.eud.cn (Zhenqiang Ni), mengzhaobo@1cu.eud.cn (Zhaobo Meng), \\ zhangbaoliang@lcu.edu.cn (Baoliang Zhang), liaorumeng@163.com (Rumeng Liao) \\ ${ }^{*}$ Corresponding author
}

\section{To cite this article:}

Ranran Pei, Zhenqiang Ni, Zhaobo Meng, Baoliang Zhang, Rumeng Liao. Characteristics of Secondary Mountain Disaster Chain in Wenchuan Earthquake. American Journal of Civil Engineering. Vol. 5, No. 6, 2017, pp. 408-413. doi: 10.11648/j.ajce.20170506.23

Received: November 14, 2017; Accepted: November 28, 2017; Published: December 28, 2017

\begin{abstract}
Tens of thousands of secondary mountain disasters such as landslides, debris flows were triggered after the Ms 8.0 Wenchuan earthquake on May 12, 2008. Large amounts of loose material were produced in gullies or on slopes, which will endanger resettled residents and destroy urban reconstruction. During the 5 years following the Wenchuan earthquake event, heavy rainfalls have already induced a great number of debris flows, barrier lakes and collapses in the earthquake-damaged area, resulting in serious casualties and property losses. The emergence and development of these disasters affect each other and are linked closely. Hence, it is important to understand the characteristics and shape of the disaster chains. In order to analyze the characteristics of secondary mountain disaster chain in Wenchuan earthquake, this paper carried out research using field survey and data statistical analysis. A large number of recording materials were reviewed and compiled to analyze more than 2440 debris flows, landslides, collapses and barrier lakes in different areas of Wenchuan, Beichuan, Dujiangyan and so on. The results showed that: the Wenchuan earthquake secondary mountain hazards are mainly distributed in Beichuan, Wenchuan, Dujiangyan and other regions near earthquake source, frequency decreases with the distance increasing source distance. The secondary disaster chain can be divided into 4 grades and 9 types, and a comprehensive type; each disaster chain consists of two or more disasters in earthquake. Precipitation and surface run off have great influence on secondary mountain disasters, and become important media for the formation of chain chains in secondary disasters. This study has some guidance to the judgment and prevention of the secondary disaster chain after earthquake.
\end{abstract}

Keywords: Wenchuan Earthquake, Secondary Mountain Disaster Chain, Regional Distribution

\section{Introduction}

China is a country with many mountains and few plains. Mountains, hills and plateaus account for $2 / 3$ of China's total area and China is also one of the countries with many earthquakes. The 2008 Sichuan earthquake also known as the First Great Sichuan earthquake or Wenchuan earthquake, occurred at 14:28:01 China Standard Time on May 12, 2008. Measuring at $8.0 \mathrm{Ms}$, the earthquake's epicenter was located 80 kilometers $(50 \mathrm{mi})$ west-northwest of Chengdu, the provincial capital, with a focal depth of $19 \mathrm{~km}$ (12 mi). Over 69,000 people lost their lives in the quake, including 68,636 in Sichuan province. 374,176 were reported injured, with 18,222 listed as missing as of July 2008. The earthquake left about 4.8 million people homeless, though the number could be as high as 11 million. The earthquake caused a large area of geomorphic changes, causing a large number of secondary mountain disasters, mainly landslides, mudslides and so on. In these secondary disasters after entering the active period, the active period of the landslide will last 5-10 years, and the active period of the debris flow will last for 10-20 years. In addition, the earthquake caused 34 Lake in Wenchuan, Beichuan and Qingchuan area, which formed in Jianjiang Tangjiashan lake, a lake in the most dangerous. The earthquake is usually accompanied by different degrees of landslides, debris flows, landslides and other geological disasters; it poses a great threat to people's lives and property. The mountain geological stability became worse after earthquake. Secondary disasters hidden mountain disaster 
chain forms, Landslide, collapse, debris flow, dammed lake and so on are the main manifestations. The emergence and development of these disasters affect each other and are linked closely. Hence, it is important to understand the characteristics and shape of the disaster chains. The characteristics and prevention technology of domestic scholars on the earthquake secondary mountain disaster chain of sense. The chain and the defense of major disasters were studied and it showed that the formation of mountain disaster chain originates from mountain disaster monomer, but the harm is far greater than the disaster monomer, harm and widely distributed (Menkepei, et al). The methods of field investigation and data simulation were used to analyze and studied the landslide disaster and disaster reduction technology in many disaster spots in Sichuan (Chenghua wang, et al.). Post-earthquake land sliding and long-term impacts were studied in the Wenchuan earthquake area, China (Runqiu Huang and Weile Li, 2014). Two types of fault models associated with the $2008 \mathrm{Mw} 7.9$ Wenchuan earthquake were reconstructed (Zhongshan Jiang, et al). One is a listric fault connecting a shallowing sub-horizontal detachment below $20 \mathrm{Km}$ depth (fault model one, FM1) and the other is a group of more steeply dipping planes further extended to the Moho at $60 \mathrm{Km}$ depth (fault model two, FM2). This paper evaluated the evolution of the debris flows that occurred after the Wenchuan earthquake, and the changes in the post-seismic debris flow activity can be categorized into three stages, i.e., active, unstable, and recession (S. Zhang and L. M. Zhang, 2017). The earthquakes-stress buildup and release associated to the 2008 Wenchuan earthquake were simulated and it provided a method of geodynamic modelling to estimate recurrence interval of large earthquakes (Chang Liu, Peiyu Dong and Yaolin Shi, 2017).

At present, there is little research on the characteristics of the Wenchuan earthquake secondary mountain disaster chain.
This paper analyzed the characteristics of secondary mountain disaster chain through field investigation and statistical analysis in the 5.12 Wenchuan earthquakes. The study results reveal the formation mechanism of the Wenchuan earthquake secondary mountain disaster chain, and provid the basis for the prevention and control of secondary disasters and give some guidance to the judgment and prevention of the secondary disaster chain after earthquake.

\section{Regional Distribution Characteristics}

According to the survey data statistics, the potential hazards of secondary new mountain in Wenchuan earthquake area reached 8627. The Wenchuan earthquake disaster counties number comparison as shown in Figure 1. According to the form of secondary disasters, there are 1694 unstable slopes and 36 dangerous lakes, resulting in 619 debris flow hazard chains. Division according to regional distribution, 285 located in Sichuan, Kitagawa, Pinwu, county, Mao County, Dujiang dam disaster area. 199 disasters were distributed in the hardest hit Songpan, Lixian, Blackwater, gold, Wangcang, Chongzhou and other small. The lake was distributed in all high-risk stricken areas. The scope of disaster chain is highly concentrated in the above 16 counties (cities) among them. Beichuan, Wenchuan, Dujiangyan and other ecological areas are extremely important areas. Cai Jia Gang Cun is located above the town of Yingxiu of Baihua bridge Niumian Mizoguchi - lotus heart - the xuankou. Wenchuan is located at the focus. Dujiangyan is about 74.45 kilometers from the epicenter. Mianzhu is about 172.38 kilometers from the epicenter and Wangcang is about 435.84 kilometers from the epicenter, county hypo central distance of about $1687.06 \mathrm{~km}$. On the whole, secondary earthquakes are frequent in the areas near the epicenter, such as Wenchuan and Beichuan, but less on the contrary.

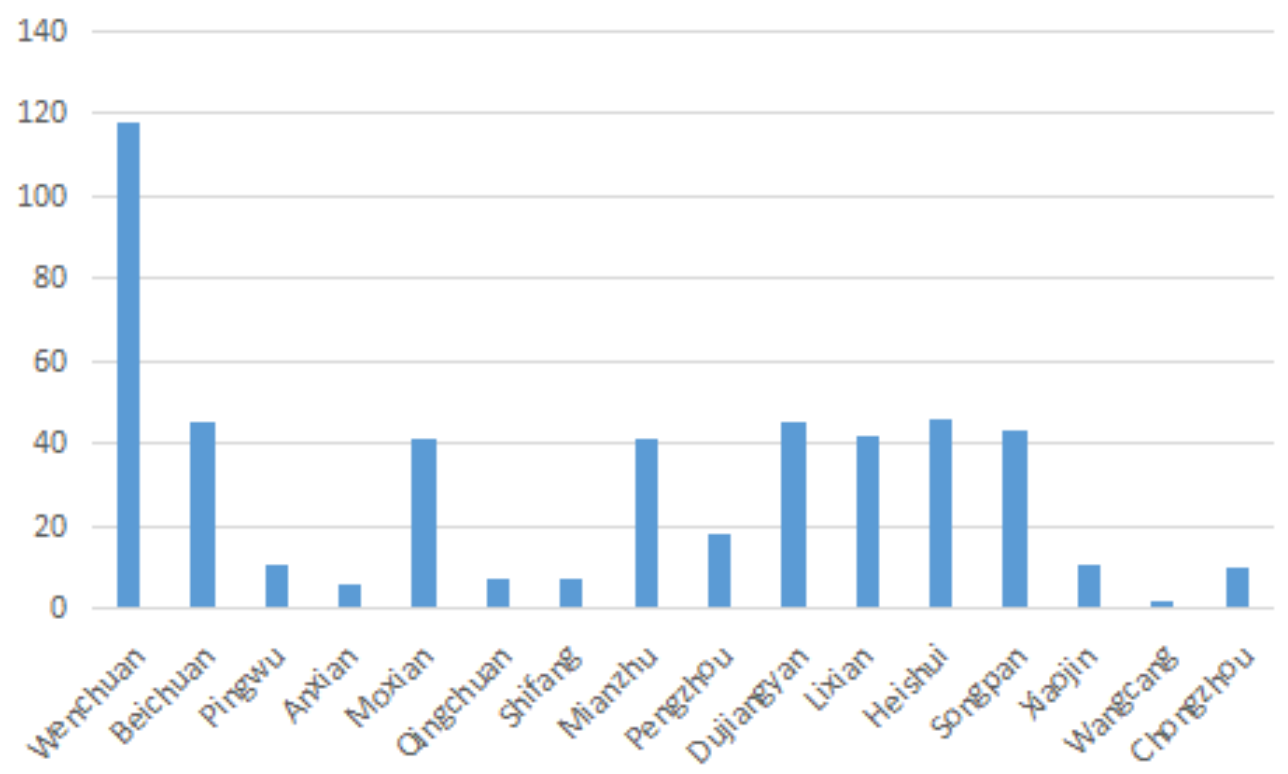

Figure 1. The Wenchuan earthquake disaster counties number comparison. 


\section{Classification Characteristics of Disasters}

According to the chain link, the Wenchuan earthquake disaster chains were divided into I, II, III, IV four different secondary mountain disaster severity levels. According to the characteristics of disaster evolution at different levels, it can be divided into 9 basic types, which is shown in Table 1 .

Table 1. Classification of disaster chain types of secondary mountain in Wenchuan earthquake.

\begin{tabular}{|c|c|c|}
\hline grade & type & evaluative feature \\
\hline I & $\begin{array}{l}\text { Earthquake to collapse hazard chain } \\
\text { Earthquake to landslide hazard chain }\end{array}$ & $\begin{array}{l}\text { At the beginning of the earthquake, the most common form of } \\
\text { disaster chain, collapse, landslide is the transition form of lower } \\
\text { level evolution of disaster chain }\end{array}$ \\
\hline II & $\begin{array}{l}\text { Earthquake to collapse to landslide hazard chain } \\
\text { Earthquake to landslide to debris flow (debris flow) disaster chain } \\
\text { Earthquake to landslide (collapse) to dammed lake disaster chain }\end{array}$ & $\begin{array}{l}\text { After the earthquake, due to other external excitation factors } \\
\text { (mainly water), landslide, landslide disaster further transformed } \\
\text { into secondary disasters }\end{array}$ \\
\hline III & $\begin{array}{l}\text { Earthquake to landslide, landslide to debris flow disaster chain } \\
\text { Earthquake to landslide to landslide to two collapse (landslide) disaster chain } \\
\text { Earthquake to landslide / landslide to dammed lake disaster chain }\end{array}$ & $\begin{array}{l}\text { After the landslide is transformed into landslide, it is transformed } \\
\text { into debris flow, dammed lake and other disaster bodies under the } \\
\text { influence of other external excitation factors (mainly water) }\end{array}$ \\
\hline IV & $\begin{array}{l}\text { Earthquake to landslide, landslide (debris flow), } \\
\text { dammed lake to mountain torrents (debris flow or debris flow) disaster chain }\end{array}$ & $\begin{array}{l}\text { This is the most complete one type for earthquake transformation, } \\
\text { when all the conditions are met, in natural or man-made lake } \\
\text { under the action of outburst flood. }\end{array}$ \\
\hline
\end{tabular}

Earthquake to collapse or landslide disaster chain is the initial form of earthquake disaster chain. The seismic moment of collapse landslide, belong to this category. Earthquake to collapse to landslide disaster chain, such as landslide in nine peak village of Pengzhou city is a large-scale landslide triggered by earthquake collapse, which was belonging to II type disaster chain type. The secondary debris flow of Wenchuan ginkgo Township ditch is on the right bank of the Minjiang River after the earthquake lcgm in rainstorm excitation earthquake - collapse landslide debris flow type. There is a lot of debris sliding in the landslide of Yingxiu Town, Yingxiu county. It belongs to the type of debris flow disaster chain from earthquake to landslide to landslide. The earthquake disasters such as landslide $\sim$ Lake chain in Yingxiu town of Laohuzui collapse to the lake, Qingchuan County donghekou Landslide Lake, Lake County of Xiaojiaqiao landslide. These all belong to III type disaster chain type. Earthquake landslide Dammed Lake flood disaster chain is the most thoroughly transformed disaster type, such as Pingwu, nanbazhen and Wenjiaba landslide dammed lake outburst flood (debris flow) of debris flow disaster chain. It belongs to the fourth level type. In general, the secondary mountain disaster chain of Wenchuan earthquake is prominent, and the space-time linkage is strong.

\section{Correlation Characteristics with Water}

Between the chain and water earthquake disasters is mainly reflected in two aspects of precipitation and surface runoff.

\subsection{Precipitation}

There is a significant correlation between quantitative statistics and rainfall distribution of collapse, landslide and debris flow disaster chain before and after the earthquake in the Wenchuan earthquake area. Rainstorm has become a sufficient condition for the evolution of landslide and debris flow disaster chain. According to the disaster relief yearbook of Sichuan province, the daily number of landslide and debris flow disaster chain in the hardest hit area of Wenchuan earthquake can be seen every month: the highest number of landslides and debris flows occurred in July and August, a total of 26 times. The total number of $91 \%$ occurred in June and September, which is shown in the table 2.

The earthquake hit a typical landslide and debris flow disaster chain can be seen on the day of rain. Most of them have chain landslide and debris flow disasters $(80 \%)$ with daily rainfall was greater than $20 \mathrm{~mm}$ precipitation. Among them, the rainfall accompanied by rainstorm accounted for $54 \%$. More than $70 \%$ days of landslide to debris flow chain are accompanied by heavy rain process. The hardest hit by the earthquake caused visible debris flow; landslide is closely related to the strong precipitation, which is as shown in the table 3 .

Table 2. The days of landslide and debris flow disaster chain in the hardest hit area of Wenchuan earthquake occur every month.

\begin{tabular}{lllllllll}
\hline Time & Apr & May & June & Jul & Aug & Sep & Oct & Total \\
\hline 1991 & - & - & - & - & - & - & - & 0 \\
1992 & - & - & 1 & 2 & - & - & - & 3 \\
1993 & - & - & - & 2 & - & - & - & 2 \\
1994 & - & - & - & 2 & 2 & - & - & 4 \\
1995 & - & - & - & - & 3 & - & - & 3 \\
1996 & - & - & - & - & 3 & - & - & 3 \\
1997 & - & - & - & - & - & - & - & 0 \\
1998 & - & - & - & - & 1 & - & - & 1 \\
1999 & - & - & 2 & - & 1 & - & - & 3 \\
2000 & - & - & - & - & - & - & 1 & 1 \\
2001 & - & 1 & - & 1 & - & 3 & - & 5 \\
2002 & - & - & - & - & - & - & - & 0 \\
2003 & 1 & - & - & 4 & 5 & - & - & 10 \\
Total & 1 & 1 & 3 & 11 & 15 & 3 & 1 & 35 \\
\hline
\end{tabular}


Table 3. Precipitation statistics of typical landslide to debris flow disaster chain in severe earthquake area over the years(mm).

\begin{tabular}{|c|c|c|c|c|c|}
\hline Year & Date & place & Place 24 hours rainfall & First 3 days rainfall & First 10 days rainfall \\
\hline 1993 & July $14^{\text {th }}-15^{\text {th }}$ & Mian Zhu & 112.6 & 11.7 & 138.2 \\
\hline \multirow{3}{*}{1994} & July $8^{\text {th }}$ & An Xian & 30.5 & 66.0 & 90.4 \\
\hline & August $20^{\text {th }}-21 \mathrm{t}^{\mathrm{h}}$ & Mian Zhu & 29.9 & 54.7 & 58.4 \\
\hline & August $9^{\text {th }}$ & Bei Chuan & 20.4 & 188.9 & 259.4 \\
\hline \multirow{3}{*}{1995} & August $9^{\text {th }}$ & An Xian & 221.9 & 160.5 & 234.6 \\
\hline & August $10^{\text {th }}$ & An Xian & 119.0 & - & - \\
\hline & August $9^{\text {th }}$ & Ping Wu & 92.0 & - & - \\
\hline \multirow{3}{*}{1996} & August $25^{\text {th }}$ & Mian Zhu & 190.1 & 4.5 & 17.0 \\
\hline & August $26^{\text {th }}$ & Mian Zhu & 44.5 & - & - \\
\hline & August $20^{\text {th }}$ & Bei Chuan & 250.7 & 252.5 & 257.0 \\
\hline \multirow{4}{*}{1998} & August $20^{\text {th }}$ & An Xian & 274.1 & 274.5 & 295.2 \\
\hline & August $20^{\text {th }}$ & Mian Zhu & 132.6 & 144.3 & 164.4 \\
\hline & August $20^{\text {th }}$ & Jiang You & 245.8 & 179.6 & 195.6 \\
\hline & June $12^{\text {th }}$ & Bei Chuan & 123.9 & 0 & 76.0 \\
\hline \multirow[t]{2}{*}{1999} & June $13^{\text {th }}$ & Bei Chuan & 149.9 & - & - \\
\hline & August $9^{\text {th }}$ & An Xian & 34.2 & 41.8 & 204.2 \\
\hline \multirow[t]{5}{*}{2000} & October $11^{\text {th }}$ & Mian Zhu & 1.1 & 23.5 & 35.7 \\
\hline & May $7^{\text {th }}$ & Chong Zhou & 2.8 & 4.4 & 40.3 \\
\hline & July $27^{\text {th }}$ & Dujiang Yan & 65.3 & 93.8 & 93.8 \\
\hline & September $18^{\text {th }}$ & Shi Fang & 71.7 & 24.1 & 39.9 \\
\hline & September $19^{\text {th }}$ & Shi Fang & 90.9 & - & - \\
\hline \multirow[t]{12}{*}{2001} & September $18^{\text {th }}$ & Mian Zhu & 35.1 & 78.1 & 95.8 \\
\hline & September $19^{\text {th }}$ & Mian Zhu & 119.4 & - & - \\
\hline & September $19^{\text {th }}$ & Mian Zhu & 259.5 & 234.7 & 271.3 \\
\hline & September $19^{\text {th }}$ & Peng Zhou & 51.6 & 3.7 & 21.0 \\
\hline & September $20^{\text {th }}$ & Peng Zhou & 46.0 & - & - \\
\hline & April $15^{\text {th }}$ & Peng Zhou & 22.5 & 1.8 & 27.1 \\
\hline & July $15^{\text {th }}$ & Wen Chuan & 5.2 & 0.2 & 2.2 \\
\hline & July $26^{\text {th }}$ & Chong Zhou & 35.4 & 6.6 & 8.4 \\
\hline & July $26^{\text {th }}$ & Dujiang Yan & 70.4 & 21.5 & 51.3 \\
\hline & July $30^{\text {th }}$ & Bei Chuan & 101.9 & 4.7 & 48.7 \\
\hline & July $31^{\text {th }}$ & Ping Wu & 25.4 & 9.6 & 13.6 \\
\hline & July $31^{\text {th }}$ & An Xian & 48.9 & 13.2 & 52.3 \\
\hline \multirow{9}{*}{2003} & July $30^{\text {th }}$ & Jiang You & 10.7 & 12.0 & 32.3 \\
\hline & August $2^{\text {th }}$ & Jiang You & 14.1 & 15.5 & 37.0 \\
\hline & August $2^{\text {th }}$ & Shi Fang & 47.8 & 71.3 & 72.9 \\
\hline & August $2^{\text {th }}$ & Dujiang Yan & 44.8 & 22.3 & 124.4 \\
\hline & August $9^{\text {th }}$ & Wen Chuan & 33.9 & 0.6 & 35.7 \\
\hline & August $9^{\text {th }}$ & Li Xian & 21.5 & 2.9 & 13.0 \\
\hline & August $9^{\text {th }}$ & Ping Wu & 38.9 & 11.2 & 147.3 \\
\hline & August $9^{\text {th }}$ & Dujiang Yan & 105.0 & 23.6 & 107.0 \\
\hline & August $29^{\text {th }}$ & Shi Fang & 107.4 & 14.8 & 133.4 \\
\hline
\end{tabular}

As shown in the table 3, some mudslides and landslides occurred in small rains. But the vast majority $(83 \%)-(10$ days or 3 days) precipitation was greater than $30 \mathrm{~mm}$. Disaster date about the weather for days of heavy rain or rainstorm day is accounts for $83 \%$. Therefore, the evolution process of landslide - debris flow disaster chain and antecedent precipitation is closely related. The formation of landslide and debris flow disaster chain is a process of cumulative evolution with precipitation.

\subsection{Surface Waste}

The water system is dense in Longmen mountain area. It has the Mingjiang River, Jialing River, Tuojiang River, Fujiang River and other important rivers system. These water systems are mountainous rivers, which are steep valley depth. The relative height difference is up to $5000 \mathrm{~m}$. A large number of landslides (avalanches) triggered by large earthquakes enter the river channel, which can easily clog the rivers and form dammed lakes. Interpretation by remote sensing, the number of quake lake in Wenchuan quake hit area up to about 260 . There are obvious harm or threat of 34,8 large dammed lakes with water volume above 3 million $\mathrm{m}^{3}, 1$ million $\mathrm{m}^{3} \sim 3$ million $\mathrm{m}^{3}$ medium-sized Lake 11,1 million $\mathrm{m}^{3}$ following a small lake in 15 places. Among them, the Tang Jiashan Lake is the largest in the vicinity of Beichuan city. The dam length is $640 \mathrm{~m}$, width is $840 \mathrm{~m}$, height is $120 \mathrm{~m}$, and the dam storage capacity is about 150 million $\mathrm{m}^{3}$. Its water storage capacity of the dammed lake increased from 16 million $\mathrm{m}^{3}$ in 18 days to 129 million $\mathrm{m}^{3}$ in 24 days. The upstream and downstream water head difference is $60 \mathrm{~m}$. So a serious threat to the safety of nearly 70 thousand people downstream.

According to the change of lake surface runoff by the formation of the situation, and combined with the existing experience at home and abroad, the harm were caused by dam break the main dam, reservoir, dam structure and storage 
time. One of the factors influences the final disposal time for maneuvering the lake. The outburst risk grading standards established for the lake formed by the earthquake. It is divided into 4 levels: high risk, high risk, medium risk and low risk, and 5 of high risk level (Xiaojiaqiao County, south of Pingwu dam, Aokawa Ishiitamizo, Mianzhu Province sword power plant upstream, Beichuan Eagle Rock Lake etc.), the dangerous level of 11. In the lower reaches of the river basin was "dangerous", since the formation of this security and economic aspects of an immeasurable threat.

\section{Linkage Mechanism}

The occurrence of mountain disasters is usually caused by more than two kinds of disasters. A mountainous disaster is often associated with other disasters or become a disaster caused by the new ring of mountain disasters in the evolution of the lag in. The debris flow and landslide evolution process associated with the most obvious. One of the main factors of debris flow formation is the supply of loose material sources. The formation of landslides also requires this substance, and the dominant factor of the formation of both is heavy rainfall. It is the abundant water supply. Covering the thick layer of loose material in mountainous area, debris flow occurs at the same time, usually accompanied by landslides. Wenchuan earthquake disaster chain types, each one disaster chain and interaction. At the same time the disaster spatial impact range is extended. Taking the secondary mountain disaster chain of Pengzhou nine peak village earthquake as an example, the upper part of the mountain collapse landslide slope of central excitation. The role of water in landslide material into the channel forming debris flow or debris flow to form the formation of lakes affect the safety of people's life and property in the lower reaches of the river. The scope from the mountain to the river, and then to tens of kilometers downstream area, which formed a disaster chain expansion effect (Figure 2).

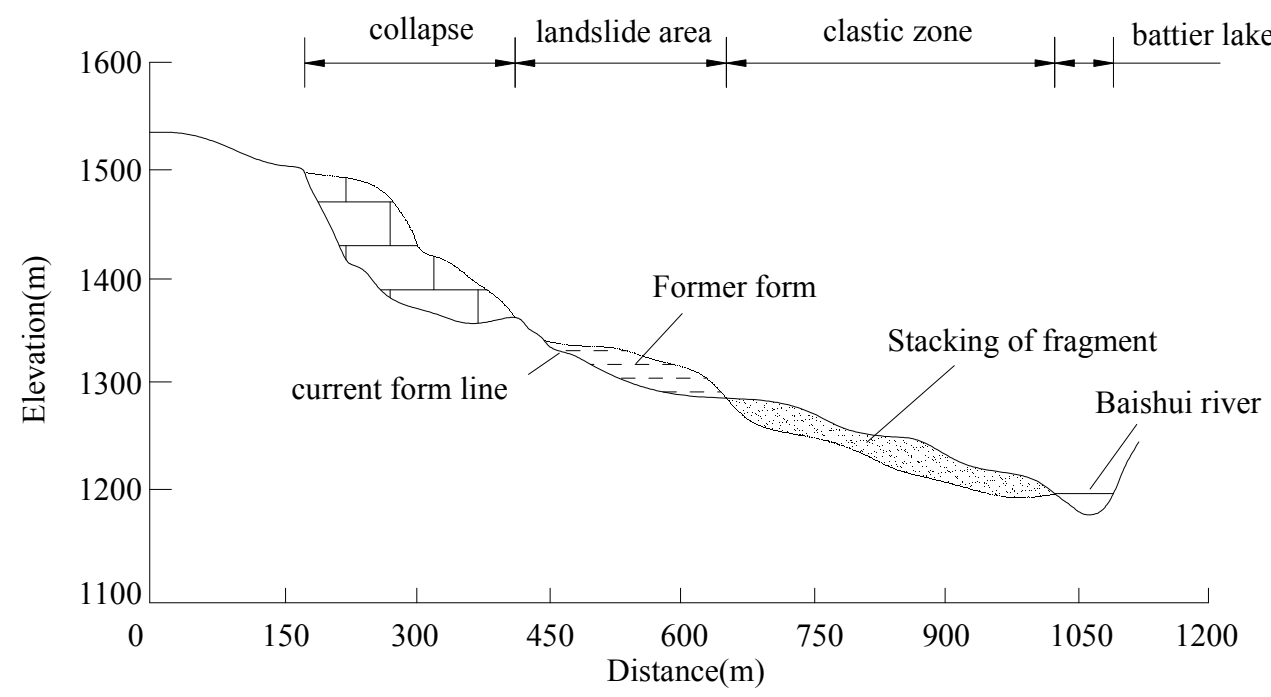

Figure 2. Formation pattern of disaster chain in nine peak village of Pengzhou.

\section{Conclusion}

In this paper, through the investigation of the earthquake disasters chain, statistical analysis showing that the Wenchuan earthquake secondary mountain disaster chain often exist in the form of debris flow. The quantity is large, the scale is huge, and the distribution is relatively concentrated. Wenchuan earthquake disaster chain type classification can be divided into four levels and nine species. The storm is become the landslide sufficient conditions of debris flow disaster chain evolution. Landslides blocked rivers into the river from Lake on the formation of the Wenchuan earthquake zone has great harm. In the secondary disaster chain of Wenchuan earthquake, each disaster body interacts and interacts with each other. Debris flow and landslide accompany each other, and also expand the spatial influence scope of the disaster.

\section{Acknowledgements}

The research described in this paper was financially supported by the National Natural Science Foundation of China (NO. 51378245), the graduate student education innovation projects in shandong province (NO. SDYY16102) and the Doctoral Research Foundation of Liaocheng University (2017).

\section{References}

[1] K. P. Men, and J. G. Jiang. "Severe disaster chain and its defense," Progress in geophysics, vol. 23, 2008, pp. 270-275.

[2] H. Xie, S. G. Shi, and J. M. Kong. "Distribution and characteristics of mountain hazards induced by the earthquake of May 12 in Wenchuan, China," Journal of Mountain Research, vol. 26. 2008, pp. 396-401. 
[3] Z. L. Zhi, P. Cui and S. M. He, "Mechanism of conversion of landslides to debris flows," vol. 14, Journal of Natural Disadters, 2005, pp. 8-14.

[4] J. M. Kong, Y. Cui, S. J. Tian and F. Y. A, "Typical Case Study on the Development Characteristics of Fragmentation-sliding Seismic Landslide," Journal of Sichuan University (Engineering Science Edition), vol. 41, 2009, pp. 119-124.

[5] S. D. Li, X. S. Ren, S. Y. Yue and H. P. Xu, "Study of Earthquake and slide," Research of Soil and Water Conservation, vol. 8, 2001, pp. 24-25.

[6] J. J. Jin, "China Mainland Earthquake Disasters and the Mitigation Suggestions in 1996 2005," Journal of Geological Hazards and Environment Preservation, vol. 18, 2007, pp. 1-5.

[7] P. Cui, F. Q. Wei, S. M. He, et al., "Mountain Disaster Induced by the Earthquake of May 12 in Wenchuan and the Disasters Mitigation," Journal of Mountain Science, vol. 26, 2008, pp. 280-282.

[8] Z. S. Jiang, L. G. Yuan, D. F. Huang, et al, "Postseismic deformation associated with the $2008 \mathrm{Mw} 7.9$ Wenchuan earthquake, China: Constraining fault geometry and investigating a detailed spatial distribution of after slip," Journal of Geodynamics, vol. 12, 2017, pp. 12-21.
[9] S. Zhang and L. M. Zhang, "Impact of the 2008 Wenchuan earthquake in China on subsequent long-term debris flow activities in the epicentral area," Geomorphology, vol. 276, 2016, pp. 86-103.

[10] R. Huang and W. Li, "Post-earthquake land sliding and long-term impacts in the Wenchuan earthquake area, China," Engineering Geology, vol. 182, 2014, pp. 111-120.

[11] M. H. Huang, R. Bürgmann and A. M. Freed, "Probing the lithospheric rheology across the eastern margin of the tibetan plateau," Earth \& Planetary Science Letters, vol. 396, 2014, pp. 88-96.

[12] Klein, E., et al. "Afterslip and viscoelastic relaxation model inferred from the large-scale post-seismic deformation following the $2010 \mathrm{Mw} 8.8$ Maule earthquake (Chile)," Geophysical Journal International, vol. 205, 2016, ggw086.

[13] Tan Hongbo, et al. "Wenchuan Ms8.0 earthquake coseismic slip distribution inversion," Geodesy and Geodynamics, vol. 6, 2015, pp. 173-179.

[14] C. Liu, P. Y. Dong, and Y. L. Shi. "Recurrence interval of the $2008 \mathrm{Mw} 7.9$ Wenchuan earthquake inferred from geodynamic modelling stress buildup and release," Journal of Geodynamics vol. 110, 2017, pp. 1-11. 